\title{
Performance Comparison and Critical Finite Element Based Experimental Analysis of Various Forms of Reinforcement Retaining Structural System
}

\author{
Aditya Kumar Tiwary ${ }^{D},{ }^{1}$ Sakshi Bhatia $\left(D,{ }^{1}\right.$ Sandeep Singh ${ }^{D},{ }^{1}$ \\ Jasgurpreet Singh Chohan $\mathbb{D}^{2},{ }^{2}$ Raman Kumar $\mathbb{D}^{2},{ }^{2}$ Shubham Sharma $\left(\mathbb{D},{ }^{3,4}\right.$ \\ S. Chattopadhyaya, ${ }^{5}$ and S. Rajkumar ${ }^{6}{ }^{6}$ \\ ${ }^{1}$ Civil Engineering Department, Chandigarh University, Mohali, Punjab, India \\ ${ }^{2}$ Mechanical Engineering Department, Chandigarh University, Mohali, Punjab, India \\ ${ }^{3}$ Department of Mechanical Engineering, IK Gujral Punjab Technical University, Main Campus, Kapurthala 144603, India \\ ${ }^{4}$ Department of Mechanical Engineering, University Centre for Research and Development and Chandigarh University, \\ Chandigarh 140413, Punjab, India \\ ${ }^{5}$ Indian Institute of Technology (ISM), Dhanbad, India \\ ${ }^{6}$ Department of Mechanical Engineering, Faculty of Manufacturing, Institute of Technology, Hawassa University, \\ Awasa, Ethiopia
}

Correspondence should be addressed to Shubham Sharma; shubham543sharma@gmail.com and S. Rajkumar; rajkumar@hu.edu.et

Received 21 November 2021; Revised 10 January 2022; Accepted 11 January 2022; Published 9 February 2022

Academic Editor: Alfrendo Satyanaga

Copyright (c) 2022 Aditya Kumar Tiwary et al. This is an open access article distributed under the Creative Commons Attribution License, which permits unrestricted use, distribution, and reproduction in any medium, provided the original work is properly cited.

\begin{abstract}
Three-dimensional finite element analysis has been carried out in order to study the response of retaining walls subjected to lateral earth pressure using ABAQUS/CAE. This study consists of analysis and design of cantilever, gravity type, and precast concrete retaining wall. It also shows comparative study such as distribution of stresses along with the deflection throughout the height of the retaining walls. The mathematical analysis procedure is adopted that entails selecting dimensions to meet the requirements of several codes and then evaluating the stability of the entire whenever the backfill load works on the wall. The stability of retaining walls in terms of sliding and overturning is evaluated. The three specified walls are then investigated using the ABAQUS software, and their behaviour is studied. In this analysis process, two components of the formed concrete wall; one is a base plate and another component is a cantilever sandwich panel, were projected. A headed anchor joins the prefabricated cantilever wall to the base plate, keeping the slab and wall together while also maintaining their integrity in the specific positions. The system requires a unique construction method for final assembly. Mainly two steps were followed for analysis: first, the different components for shear and bending moments, namely, heel and footplates, were designed, and then, the stability of the whole structure under load was evaluated. The ABAQUS program was used to simulate and analyse the stability of various walls, including traditional and precast concrete retaining walls. It was found on the basis of the observation that the prefabricated retaining wall is the most viable option out of the three as the stress and deflection in the former type are lowered.
\end{abstract}

\section{Introduction}

Retaining walls are being used to sustain steep or nearvertical backfills in practically most construction projects. Gravity retaining walls are typically rigid nonyielding retention walls. The scale of such gravity retention walls is substantial. In some cases, towering retaining structures may be designed to withstand lateral earth pressure. Huge gravity walls, on the other hand, may not be feasible because of cost and location limits [1]. Since cantilever barriers do not need specific soil stabilisation and are less vulnerable to damage, they are still very widespread in urbanized regions. They 
often compete successfully if the wall length is between 20 and $50 \mathrm{~m}$ and not particularly high [2]. Nevertheless, because of physical constraints, significant yielding of stiff cantilever retention walls may not even be practicable, and these walls must be constructed to withstand higher earth pressures than the active earth pressures. In recent years, the application of panel-type retaining walls is expanding in order to improve these retaining wall problems [3]. By applying the precast panel, the problems such as air delay and deterioration of concrete quality caused by concrete casting in the existing retaining wall have somewhat been solved. The panel-type retaining wall is a construction method that protects and reinforces the strength of the original ground as much as possible. Unlike general gravity retaining walls, it increases the shear strength of the original ground by reinforcing support materials such as soil nailing, ground anchor, and earth bolt and uses the precast panel and support material as the front panel. It is a construction method that resists horizontal earth pressure by fastening to form individual walls [4].

In the design of traditional retaining wall systems, the most important component is the determination of active and passive lateral earth pressure coefficients, particularly under seismic load, and many studies were conducted and summarized [5-8]. In the current history, a large number of research approaches have been used to investigate conventional slopes and walls as well as reinforced fill. The experimental examination of infrastructures is one aspect of reinforced soil research [9-13]. Gravity retaining walls have been planned and built in huge numbers around the world because of their economic feasibility along with technological advantages. Retaining structures in fortified grounds have grown in popularity over the last couple of decades, particularly back-to-back reinforcing soil for embankments reaching crossings to elevated heights. The 2D FE computer package, FLEX, was used to develop a finite element analytical simulation of gravity walls found on dry sand [14-16]. Gazetas et al. [7] used the commercial FE program ABAQUS to create mathematical simulations for 2D plane-strain circumstances. The behaviour of counterfort, as well as cantilever retaining walls under lateral earth pressure, was studied employing 3D finite element modelling utilizing ABAQUS/standard [17]. Three cantilevers and one counterfort retaining wall of varied geometrical arrangements were investigated. In the case of the cantilever retaining wall, the stresses and deformations increased as the height of the structure increased. The highest values of stress were observed in the arrangements with a more toe-less heel, whereas the highest values of horizontal deformation with more heel-less toe arrangement of the wall were observed. The highest compression (in reinforcement along with concrete) was deemed to be located close to the stem and toe junction, while peak tension was located close to the shear key and toe as well as stem and heel junctions $[18,19]$.

The research was reported that described the prefabricated ultra-high performing concrete (UHPC) cantilever retaining wall's construction and design [20]. This retaining wall was analysed and designed in line with geotechnical design criteria given in EC-7, as well as the JSCE guidelines for UHPC structural designing and construction. The prefabricated UHPC wall was correlated to the "traditional" prefabricated RC retaining wall in terms of environmental efficiency. As per the findings, in terms of emissions of $\mathrm{CO}_{2}$, the greenhouse effect, basic material spending, and embodied energy, the prefabricated UHPC retaining wall performed better when contrasted to the "traditional" prefabricated RC wall. Also, the requirement of reinforcing steel was reduced using the prefabricated UHPC retaining wall.

A cantilevered type retaining wall comprised of concrete and steel reinforcement was designed and analysed [21, 22]. The shape of the wall was like an inverted T. The estimation of the primary dimensions of the wall was also included. The safety factor regarding bearing pressure, sliding, and overturning was also calculated. The resistance against shear at the bottom was calculated using ACI codes, and tensile stress at the base and the stem, as well as the reinforcements, were predicted for every element. A total of 30 retaining walls with different heights were assessed in a study [23]. Different permissible soil stresses were involved, i.e., $0.2,0.3$, and $0.4 \mathrm{MPa}$. The evaluation method took into account the impact on the environment. Also, the contribution range of elements to each impact was observed. Concrete, transport landfill, formwork, machinery, and steel were the elements incorporated in the analysis.

The goal of this study is to develop traditional (cantilever and gravity alone) and prefabricated retaining walls, examine their overall stability, and utilize ABAQUS software to analyse them to see if the prefabricated retaining walls are a class equivalent and cost-effective option of the traditional retaining wall or not. Most retaining walls are built using traditional casting methods and techniques [24-28]. Since, there are just a few methods for using prefabricated retaining walls caused by the shortage of research and scientific data. No detailed experimental research has been conducted on precast retaining walls in highway and bridge applications. Therefore, these precast retaining wall systems have not been discovered worldwide [26].

1.1. Cantilever Retaining Wall. This type of wall is usually composed of reinforced concrete with an inverted " $T$ "shaped structure. Its working principle is the principle of leverage. It basically consists of three parts, namely, rod, heel plate, and socket. The stems on these walls are thinner and use the weight of the padding to provide most of the slip and roll resistance. These walls are shown in the following image. These walls have proven to be economical at heights of up to 6-7 m. Each component has a cantilever design. The floor weight over the heel aids in maintaining the wall's upright position. L-shaped walls may be found on several of these structures. The key is that there is a vertical projection under the wall to enhance resistance against slip. The study involves first the use of some parameters given in excel format to design the cantilever retaining wall and then employing ABAQUS software $[14,17,21,23]$ to analyse its stability as shown in Figure 1. 


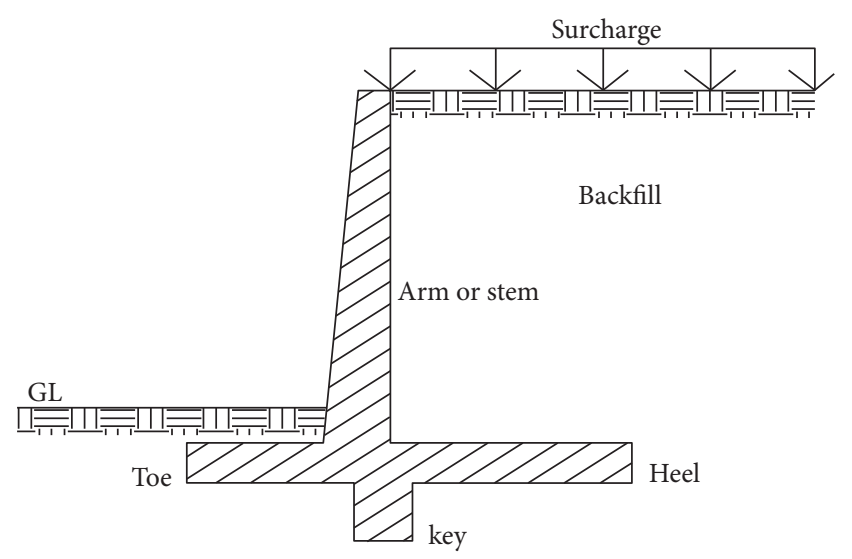

FIgURE 1: Cantilever retaining wall.

1.2. Gravity Type Retaining Wall. Gravity type retaining walls are primarily built to withstand the pressure of the earth using their own weight. Mass concrete, stone, or brick masonry are used to construct them. Walls can be cast in any shape and size using the correct design practices and code recommended specifications. However, these walls have proven to be uneconomical even for heights over $6 \mathrm{~m}$. The main reason for this limitation is the need for a large foundation width [9-11]. Damaged walls are easier to repair and also intended for static loads; thus, seismic forces are not taken into account while designing these walls. In the actual work, however, one also works constructively according to the site conditions and regulations in the standard specification. Some other factors such as drainage and substructure requirements are also need to be taken into account. These factors make these walls work, and proper design is also taken into account in the design [12]. Figure 2 shows a gravity retaining wall.

1.3. Precast Concrete Retaining Wall. In this type, reinforced concrete retaining wall panels are constructed of concrete and supplied to the construction site [29-31]. These walls are built to the appropriate size in industrial plants before being delivered to the construction site. The plates are made under strict guidelines to ensure high quality [26]. If large structures are to be built, precast concrete is a more cost-effective construction method. Figure 3 shows an example of the prefabricated retaining wall.

\section{Mathematical Analysis}

The process of design begins by selecting dimensions based on the requirements of codal provisions, and afterwards, the total strength of the structure is determined once the load from the backfill acts on the wall. Then, a prefabricated retaining wall panel is created for the same load circumstances, and its integrity in terms of sliding and overturning is assessed. The behaviour of the three specified walls is examined using ABAQUS software. The design work focuses on the computation of the total structure's stability during loading conditions and failure mechanisms.
2.1. Design Computations of Cantilever Type Retaining Wall. The parameters used in designing the cantilever retaining wall are given in Table 1.

2.1.1. Calculations of Preliminary Dimensions. (1) Depth of foundation: as per code, the minimum depth of foundation is $D_{\min }$ and is calculated as

$$
\begin{array}{r}
D_{\text {min. }}=\frac{\operatorname{SBC}}{\gamma}\left(K_{a}\right)=\frac{150}{18} \times\left(\frac{1}{3}\right)^{2}=1.08 \mathrm{~m}, \\
\text { Provided foundation depth as } 1.20 \mathrm{~m},
\end{array}
$$

$$
\text { Retaining wall's total height }=5.5+1.2=6.70 \mathrm{~m} \text {. }
$$

(2) Base width: the minimum breadth of the base in a $\mathrm{T}$-shaped retaining wall is computed by the following formula,

$$
\begin{aligned}
b & =\sqrt{3 P} 2 \gamma, \\
P & =\frac{1}{2} \times K_{a} \times \gamma \times H^{2}, \\
P & =\frac{1}{2} \times \frac{1}{3} \times 18 \times 6.7^{2}=134.67 \mathrm{kN}, \\
b & =\sqrt{3} \times 134.672 \times 18=3.35 \mathrm{~m} .
\end{aligned}
$$

Consider toe width $=\frac{b}{3}$

$$
\begin{aligned}
& =\frac{1}{3} \times 3.35 \\
& =1.12 \mathrm{~m} .
\end{aligned}
$$

Total width of base $=4 \mathrm{~m}$.

Base slab thickness $=\frac{H}{12}$ to $\frac{H}{15}$.

In between 0.558 to 0.446 .

Considering uniform thickness $=500 \mathrm{~mm}$.

(3) For stem:

$$
\begin{aligned}
\text { Base pressure of stem } & =K_{a} \times \gamma \times h . \\
\text { Here, } h & =6.70-0.50 \\
& =6.20 \mathrm{~m},
\end{aligned}
$$

Maximum base moment $=\left(\frac{1}{2} \times K_{a} \times \gamma \times h^{2}\right) \times \frac{h}{3}$

$$
\begin{aligned}
& =\left(\frac{1}{2} \times \frac{1}{3} \times 18 \times 6.20^{2}\right) \times \frac{6.20}{3} \\
& =238.32 \mathrm{kNm} .
\end{aligned}
$$

Factored moment $=1.5 \times 238.32$

$$
=357.48 \mathrm{kNm} \text {. }
$$

(4) For Fe 415 steel: 


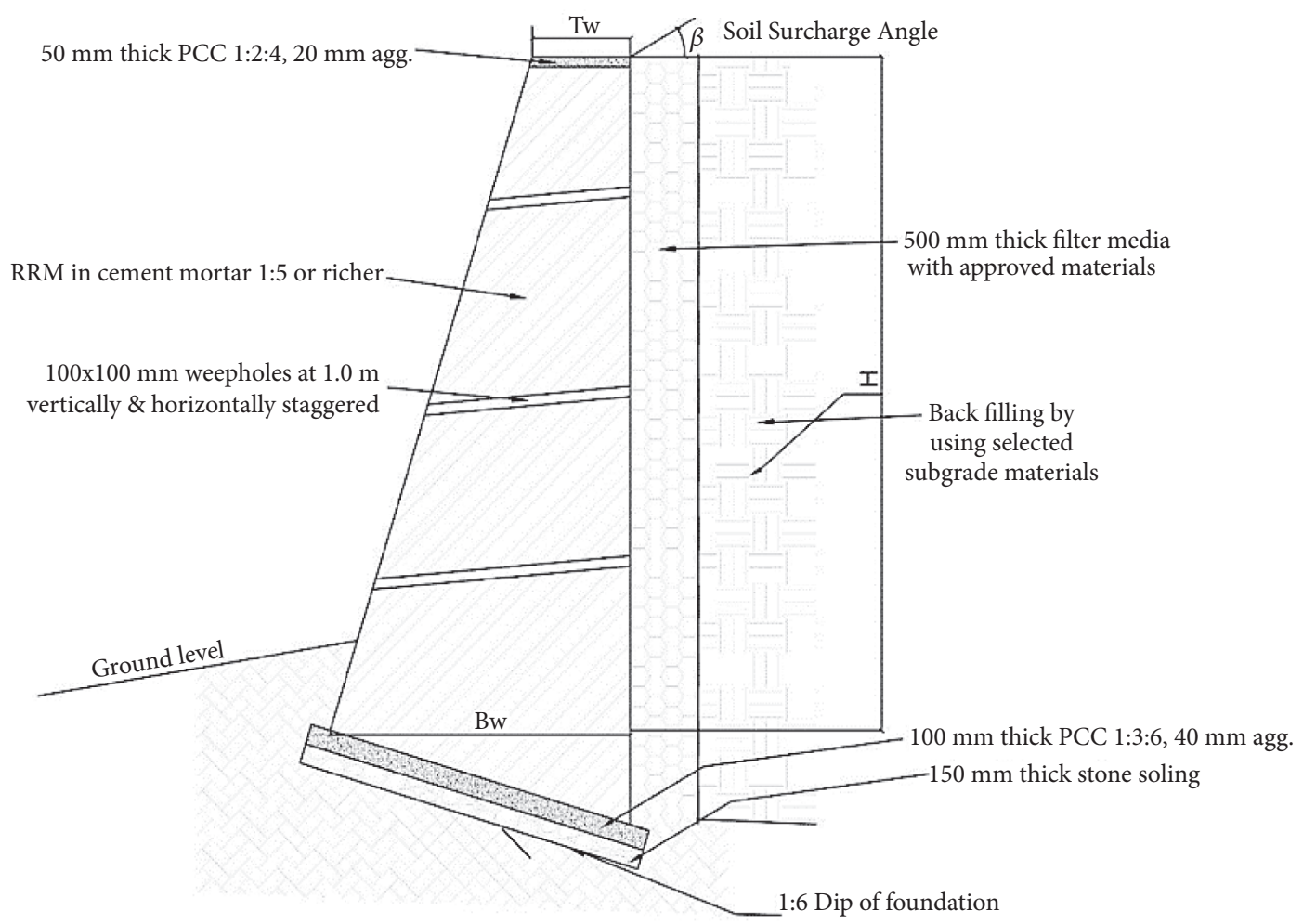

FIGURE 2: Gravity type retaining wall.

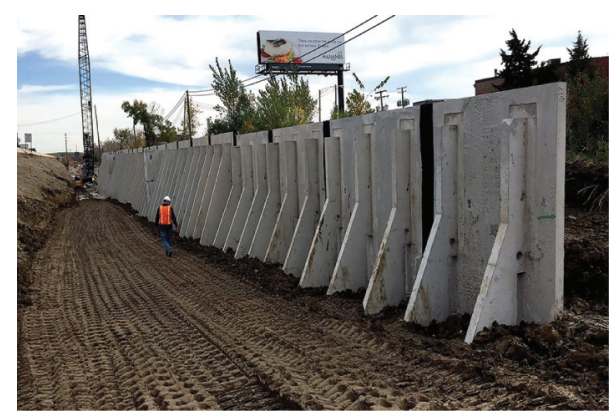

Figure 3: Precast retaining wall.

TABLE 1: Design parameters for the cantilever retaining wall.

\begin{tabular}{lcc}
\hline Parameters & Notation & Value \\
\hline Wall height & $h$ & $3.8 \mathrm{~m}$ \\
Backfill soil density & $\Upsilon_{s}$ & $18 \mathrm{kN} / \mathrm{m}^{2}$ \\
Angle of surcharge & $\beta$ & $15^{\circ}$ \\
Angle of repose & $\phi$ & $30^{\circ}$ \\
Density of concrete & $\Upsilon_{c}$ & $25 \mathrm{kN} / \mathrm{m}^{2}$ \\
Soil's safe bearing capacity & $\mathrm{SBC}$ & $150 \mathrm{kN} / \mathrm{m}^{2}$ \\
Coefficient of friction between concrete & $\mu$ & 0.5 \\
and soil & $f_{c k}$ & $25 \mathrm{~N} / \mathrm{mm}^{2}$ \\
Grade of concrete & $f_{\mathrm{y}}$ & $415 \mathrm{~N} / \mathrm{mm}^{2}$ \\
Yield strength of steel & - & 1.5 \\
Factor of safety & - & $50 \mathrm{~mm}$ \\
Effective cover & &
\end{tabular}

$$
\begin{aligned}
M_{u} & =0.138 \times f_{c k} \times b \times d^{2}, \\
357.48 \times 106 & =0.138 \times 25 \times 1000 \times d^{2}, \\
d & =359.89 \mathrm{~mm} .
\end{aligned}
$$

By considering an effective cover of $50 \mathrm{~mm}$,

$$
\begin{aligned}
\text { Overall required “ } d \text { ” for stem } & =359.89+50 \\
& =409.89 \mathrm{~mm} .
\end{aligned}
$$

Provide a whole stem depth of $450 \mathrm{~mm}$. Provide a stem with a top width of $0.20 \mathrm{~m}$.

(5) For heel and shear key:

$$
\text { Heel width }=(4.00-1.20-0.45)=2.35 \mathrm{~m} .
$$

To keep the wall from sliding, a shear key, below the base, with dimensions $450 \times 500 \mathrm{~mm}$ is provided (Figure 4).

2.1.2. Computation of Loading and Moments. Tables 2 and 3 quantify all of the service loads operating on the retaining structure in either a vertical or horizontal manner.

2.1.3. Checks for Safety Factor. Provide a distance of CG of all vertical loads from the toe's face, i.e., A.

$\sum W=\bar{x}=$ net moment at $\mathrm{A}$ (toe): 


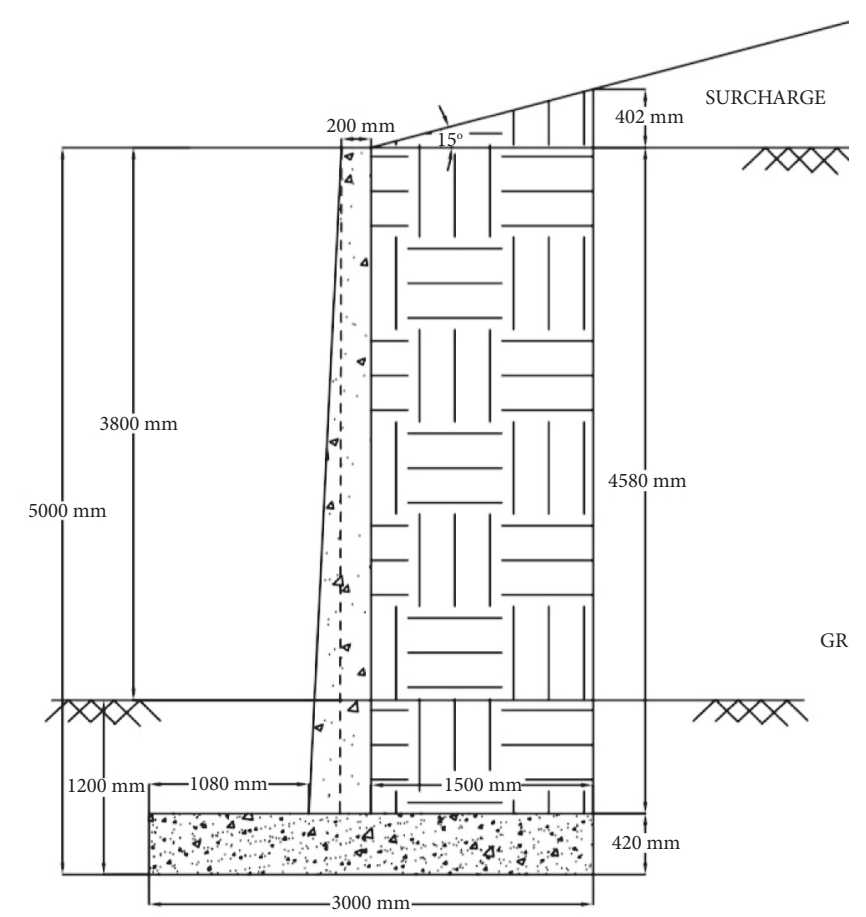

FIGURE 4: Final calculated dimension of cantilever retaining wall.

TABLE 2: For horizontal loads.

\begin{tabular}{lccc}
\hline Load & Horizontal load $(\mathrm{kN})$ & $\begin{array}{c}\text { Perpendicular } \\
\text { distance from } \\
\mathrm{A}(\mathrm{m})\end{array}$ & $\begin{array}{c}\text { Moment } \\
\text { about A } \\
(\mathrm{kNm})\end{array}$ \\
\hline $\begin{array}{l}\text { Active earth } \\
\text { pressure }\end{array}$ & $1 / 2 \times 40.2 \times 6.7=134.67$ & $6.7 / 3=2.23$ & 300.31 \\
Total & 134.67 & & 300.31 \\
\hline
\end{tabular}

$$
\bar{x}=\frac{923.49-300.31}{368.26}=1.69 \mathrm{~m},
$$

Hence, eccentricity $(e)=\frac{b}{2}-\bar{x}=\frac{4}{2}-1.69=0.31 \mathrm{~m}$.

(1) Maximum pressure at toe (A):

$$
\begin{aligned}
P_{\text {max. }} & =\frac{\sum W}{b}\left(1+\frac{6 e}{b}\right) \\
& =\left(\frac{368.26}{4}\right)\left[1+6 \times \frac{0.31}{4}\right] \\
& =\frac{134.86 \mathrm{kN}}{\mathrm{m}^{2}}<150(\mathrm{SBC}) .
\end{aligned}
$$

Hence safe.

$$
\begin{aligned}
P_{\text {min. }} & =\frac{\sum W}{b}\left(1-\frac{6 e}{b}\right) \\
& =\left(\frac{368.26}{4}\right)\left[1-\left(6 \times \frac{0.31}{4}\right)\right] \\
& =\frac{49.25 \mathrm{kN}}{\mathrm{m}^{2}}>0 .
\end{aligned}
$$

Since $P_{\min }$ is higher than 0 , there is no tension at the base. Therefore, safe.

(2) Safety factor against overturning:

$$
\text { Resisting moment }=923.49 \mathrm{kNm} \text {, }
$$

Overturning moment $=300.31 \mathrm{kNm}$,

$$
\begin{aligned}
\text { Factor of safety } & =\frac{923.49}{300.31} \\
& =3.07>1.55, \text { safe. }
\end{aligned}
$$

(3) Safety factor against sliding:

Sliding force $=134.67 \mathrm{kN}$,

Frictional force $=\mu \times \sum W$

$$
=0.5 \times 368.26=184.13 \mathrm{kN} \text {. }
$$

Passive pressure under the key base:

$$
\begin{aligned}
P_{p} & =K_{p} \times \gamma \times h_{1}=3 \times 18 \times 1.0 \\
& =54 \mathrm{kN}, \quad \text { as }\left(h_{1}=0.5+0.5=1 \mathrm{~m}\right) .
\end{aligned}
$$

Total $P_{p}=\frac{1}{2} \times 54 \times 1.0=27 \mathrm{kN}$,

$$
\begin{aligned}
\text { FS } & =\frac{\text { Restoring force }}{\text { Sliding force }} \\
& =\frac{211.13}{134.67} \\
& =1.57>1.55,
\end{aligned}
$$

hence safe. 
TABLE 3: For vertical loads.

\begin{tabular}{lccc}
\hline Load & Horizontal load $(\mathrm{kN})$ & $\begin{array}{c}\text { Perpendicular distance } \\
\text { from A }(\mathrm{m})\end{array}$ & $\begin{array}{c}\text { Moment about A (kNm) } \\
\text { Stem W1 }\end{array}$ \\
Stem W2 & $(6.20 \times 0.2 \times 25)=31$ & $1.2+0.25+0.1=1.55$ & 48.05 \\
Base slab W3 & $(4 \times 0.25 \times 6.2 \times 25=19.375$ & $1.2+(2 / 3 \times 0.25)=1.37$ & 26.54 \\
Shear key W4 & $(0.45 \times 0.50 \times 25)=5.625$ & $4 / 2=2.0$ & 100.00 \\
Backfill W5 & $(2.35 \times 6.2 \times 18)=262.26$ & $1.2+0.45+2.35 / 2=2.825$ & 8.02 \\
Total load LW & $368.26 \mathrm{kN} \downarrow$ & & 740.88 \\
\hline
\end{tabular}

Total downward load $=368.26 \mathrm{kN}$. Resisting moment $=923.49 \mathrm{kNm}$.

2.2. Designing of Gravity Type Retaining Wall. The data used in designing gravity retaining walls are given in Table 4.

2.2.1. Computation of Dimensions. In this step, the wall's top and base widths are estimated using the designing table shown in Figure 5 based on their relative heights (Table 5).

2.2.2. Computations of Loading and Moments. All service loadings are opposed by the wall's own weight. The only force preventing all applied loads is the wall's weight exerting in a vertical motion. Table 6 provides how the forces are calculated. At H/3 height from the wall's base, active earth pressure $P_{h}$ operates.

\subsubsection{Checks for Safety Factors}

(1) For overturning:

$$
\begin{aligned}
\frac{\sum M_{R}}{M_{o}} & \geq 2.0=\frac{336.43}{85.93} \\
& =3.92 \geq 2.0,
\end{aligned}
$$

Hence safe,

where $\sum M_{R}$ represents the total restoring moment and $M_{o}$ represents the overturning moment.

(2) For sliding:

$$
\begin{aligned}
\frac{\left(\mu \times \sum W\right)}{P_{h}} & \geq 1.55=\frac{(0.5 \times 185.76)}{59.95} \\
& =1.55, \quad \text { Hence safe }
\end{aligned}
$$

where $\sum W$ represents the total load acting vertically, $\mu$ represents the coefficient of friction, and $\mathrm{Ph}$ represents the active earth pressure.

(3) For bearing pressure:
TABLE 4: Data for gravity retaining wall design.

\begin{tabular}{lcc}
\hline Parameters & Notation & Value \\
\hline Soil's safe bearing capacity & $\mathrm{SBC}$ & $150 \mathrm{kN} / \mathrm{m}^{2}$ \\
Masonry density & $\Upsilon_{m}$ & $24 \mathrm{kN} / \mathrm{m}^{2}$ \\
Backfill soil density & $\Upsilon_{s}$ & $18 \mathrm{kN} / \mathrm{m}^{2}$ \\
Angle of repose & $\phi$ & $30^{\circ}$ \\
Angle of surcharge & $\beta$ & $15^{\circ}$ \\
Frictional coefficient between soil and & $\mu$ & 0.5 \\
concrete & \multicolumn{1}{c}{} \\
Wall height & $\mathrm{h}$ & $3.8 \mathrm{~m}$ \\
\hline
\end{tabular}

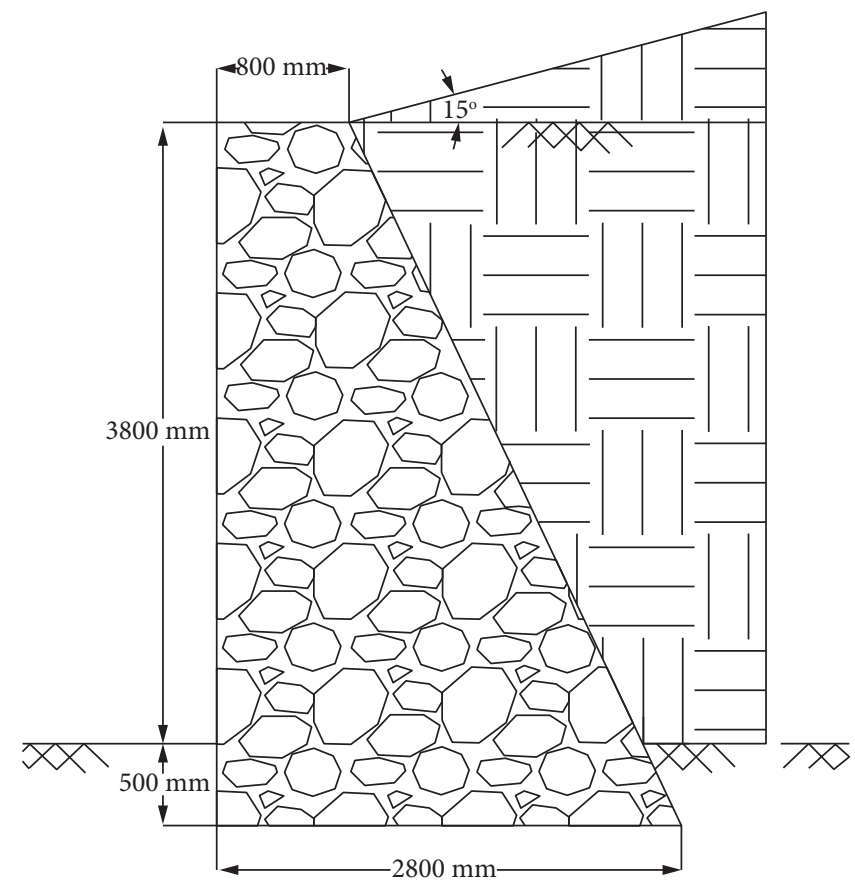

FIGURE 5: Calculated dimensions of gravity retaining wall. 
TABle 5: Design standard with a surcharge load.

\begin{tabular}{|c|c|c|c|c|c|c|}
\hline \multirow{3}{*}{ Height (m) } & \multicolumn{6}{|c|}{ Surcharge angle up to $15^{\circ}$} \\
\hline & \multicolumn{2}{|c|}{ SBC 80} & \multicolumn{2}{|c|}{ SBC 100} & \multicolumn{2}{|c|}{ SBC 150} \\
\hline & Base width & Top width & Base width & Top width & Base width & Top width \\
\hline 1 & 0.5 & 0.45 & 0.5 & 0.45 & 0.5 & 0.45 \\
\hline 2 & 0.9 & 0.5 & 0.9 & 0.5 & 0.9 & 0.5 \\
\hline 3 & 1.55 & 0.5 & 1.55 & 0.5 & 1.55 & 0.5 \\
\hline 4 & 2.2 & 0.6 & 2.2 & 0.6 & 2.2 & 0.6 \\
\hline 5 & 3.85 & 0.8 & 3.5 & 0.8 & 2.65 & 0.8 \\
\hline 6 & 4.9 & 1 & 4.7 & 1 & 4.1 & 1 \\
\hline
\end{tabular}

TABLE 6: Moments and loading calculations.

\begin{tabular}{lcccc}
\hline Load & Load magnitude $(\mathrm{kN})$ & & Distance of toe $(\mathrm{m})$ & $\begin{array}{c}\text { Moment about the } \\
\text { toe }(\mathrm{kNm})\end{array}$ \\
\hline$W 1$ & $(0.8 \times 4.3 \times 24)$ & 57.60 & 2.4 & 198.144 \\
$W 2$ & $0.5 \times(2.8-0.8) \times 4.3 \times 24$ & 103.2 & 1.34 & 138.29 \\
$\sum W$ & - & 185.76 & - & 336.43 \\
$\sum_{\mathrm{M} R}$ & - & 336.43 & - & - \\
$\mathrm{Ph}$ & $K_{a} \times \gamma \times H^{2} / 2$ & 59.95 & 1.43 & 85.93 \\
\hline
\end{tabular}

$$
\begin{aligned}
x & =\frac{(\text { Resultant moment at toe })}{\sum W} \\
& =\frac{(336.43-85.93)}{185.76} \\
& =1.35 \mathrm{~m}, \\
e & =\left(\frac{B_{w}}{2}\right)-\mathrm{x}, \\
e & =\left(\frac{2.8}{2}\right)-1.35 \\
& =0.05 \mathrm{~m}, \\
P_{\max .} & =\frac{\sum W}{b}\left(1+\frac{6 e}{b}\right) \\
& =\left(\frac{185.76}{2.8}\right)\left[1+\left(6 \times \frac{0.05}{2.8}\right)\right] \\
& =73.66 \mathrm{kNm}<\mathrm{SBC},
\end{aligned}
$$

hence safe,

where $e$ represents the eccentricity, $B_{w}$ is the base width, $P_{\max }$ is the maximum pressure at the toe, and $P_{\min }$ is the minimum pressure at the toe.

$$
\begin{aligned}
P_{\text {min. }} & =\frac{\sum W}{b}\left(1-\frac{6 e}{b}\right) \\
& =\left(\frac{185.76}{2.8}\right)\left[1-\left(6 \times \frac{0.05}{2.8}\right)\right] \\
& =59.03 \mathrm{kNm}>0,
\end{aligned}
$$

hence safe.
2.3. Prefabricated Retaining Wall Layout. A prefabricated retaining wall technology is proposed to replace traditional retaining structures, as shown in Figure 6. Two parts are used in the design: (a) a prefabricated wall panel and (b) a levelling pad.

2.3.1. Precast Wall Panel. As shown in Figure 6, it is an L-shaped structure with the stem in the vertical direction and heel slab in the horizontal direction. Dowels are inserted through weep-holes in the bottom section. Fasteners for fixing geomembranes and geogrids are also provided. The geomembranes and heel slab oppose the overturning moment, while the shear key and the dowels at the bottom resist sliding.

2.3.2. Levelling Pad. This part is shaped like an inverted L. One arm serves as a wall panel's levelling surface, while the other serves as a shear key. Anchorage bars or dowels with a diameter of $25 \mathrm{~mm}$ are also incorporated into the vertical arm.

\section{Finite Element Modelling}

The interplay of different components of retaining structures can be investigated using numerical simulation. This could aid in a clearer appreciation of retaining wall responsive attributes. The fundamental benefit of using a finite element model to analyse a soil-structure contact concern is how it can possibly account for diversity in the structure or soil media, as well as discontinuities in the geometry and materials. ABAQUS/CAE (computer-aided engineering) is utilized to create a finite element model of the retaining wall. ABAQUS/CAE is a software tool that may be used in modelling and analysing mechanical components, parts, and assemblies (preprocessing), as well as predicting the results of finite element analysis. This program offers precise, robust, and high-efficiency solutions to nonlinear issues, as 


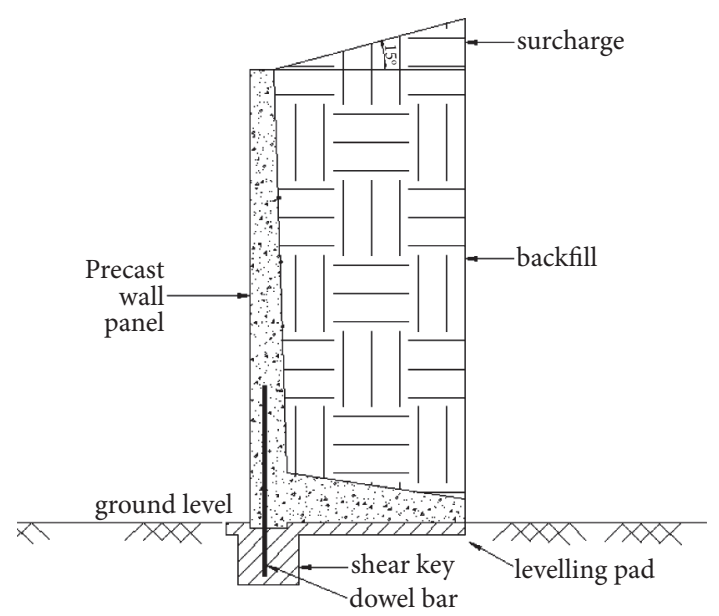

FIgURE 6: Proposed prefabricated cantilever retaining wall.

well as a wide range of linear dynamics applications and regular design simulations. This program aids in the creation and import of geometry from scratch. It enables users to employ the whole spectrum of analytical functions, such as acoustics, connections, damage, fracture, and failure, strategically. Steps, interactions, sections, and contents are all familiar ABAQUS principles, making the interface with the user more user-friendly. The simulation of the retaining wall is carried out using the finite element package ABAQUS. The reinforcement was modelled as a $3 \mathrm{D}$ truss and the concrete as a $3 \mathrm{D}$ deformable body. The constraint function in ABAQUS/tie CAE was used to model the concrete and steel's interaction, with the concrete considered to represent the host area and the steel as the embedding region. The closest concrete node determined the degree of freedom of the steel. 8-noded linear hexahedral reduced integration (C3D8R) elements were utilized to mesh concrete, which was reinforced by a 2-noded linear truss element.

\subsection{Creation of Geometry of Retaining Wall. For strength and} structural integrity, the retaining walls were designed manually. ABAQUS/CAE was utilized to create an analytical model for the retaining walls. The retaining walls' dimensions and reinforcement were modelled using the same formula as the design as given in Tables 1 and 4 . The soil depth beneath the floor slab was determined using the Boussinesq equation on the basis of the distribution of stress beneath the base slab.

The initial phase in software analysis is to create geometric shapes of various types of retaining walls. The size value is obtained from the numerical method performed in the previous section, and on this basis, geometrics are created for all walls in the software. These are shown in Figures 7(a) and 7(b).

3.2. Material Modelling. In this research, the following material characteristics are analysed. Three different types of materials are utilized to create the walls, as given in Table 7 . The reinforcement was considered as a 3D truss, whereas the concrete was simulated as a $3 \mathrm{D}$ deformable component. In this investigation, M25 concretes with elastic modulus $\left(E=4700 \sqrt{ } f_{c}\right)$ and Fe 415 steel were used. The modulus of elasticity of stone obtained was $14270 \mathrm{~N} /$ $\mathrm{mm}^{2}(E=\sigma / \varepsilon)$, where $\sigma=142.7 \mathrm{~N} / \mathrm{mm}^{2}$, and $\quad \varepsilon=0.01$. ASTM C 128 (AASHTO T 84) and ASTM C 128ASTM C 127 (AASHTO $T$ 85) contain information on stone density as well as more precise water density estimates. The density for the most natural stones ranges from 2400 to $2900 \mathrm{~kg} / \mathrm{m}^{3}$. The interface involving steel and concrete was simulated employing ABAQUS/tie CAE's constraint option, with the concrete considered being the hosting part as well as the steel considered to become the inserted part. The steel's degree of freedom was determined by the closest concrete node. The general contact algorithm was considered to define the interaction among the concrete and the adjacent soil, where the concrete serving as the first surface and the soil serves as the second. A frictional coefficient of 0.4 was established between the earth and the concrete. In this investigation, the material behaviour of concrete, soil, and steel was assumed to be linear elastic.

3.3. Load and Boundary Conditions. The next stage is to introduce service loads and boundary conditions after creating the geometry and assigning material attributes; the wall pressure was calculated in this case, and afterwards, the load was applied directly to the models. For analysis of cantilever and precast retaining wall, loading was applied as per mathematical calculation as given in Tables 2 and 3. The boundaries of soil were constrained regarding all Dof's. The constraints use the insert option, and the floor surface is totally fixed in this context and must not move or rotate in any direction. The active and passive pressures were determined numerically by applying basic arithmetic formulas that are a parameter of the wall height and that were included in the computations. Gravitational body force was given to the earth and concrete's self-weight.

3.4. Meshing of Models. The impact of mesh size on computational results was investigated using a finite element model to guarantee that the modelling done was correct and suitable. The mesh size was regarded fine for all produced models, and the element size was $0.25 \mathrm{~m}$, with the anchor size being $0.25 \mathrm{~m}$ in all the models as shown in Figures $8(a)-8(d)$.

\section{Results and Discussion}

4.1. Stress Distribution and Deflection in Gravity Type Retaining Wall. For gravity retaining walls, Figure 9 shows the deflection and distribution of stress along with the wall's height. As shown in Figure 9(a), the maximum stress in the gravity retaining wall was observed at the bottom while minimum on the wall's top. The maximum deflection in this wall type was observed on the wall's top part, whereas minimum deflection was observed on its bottom as shown in Figure 9(b). 


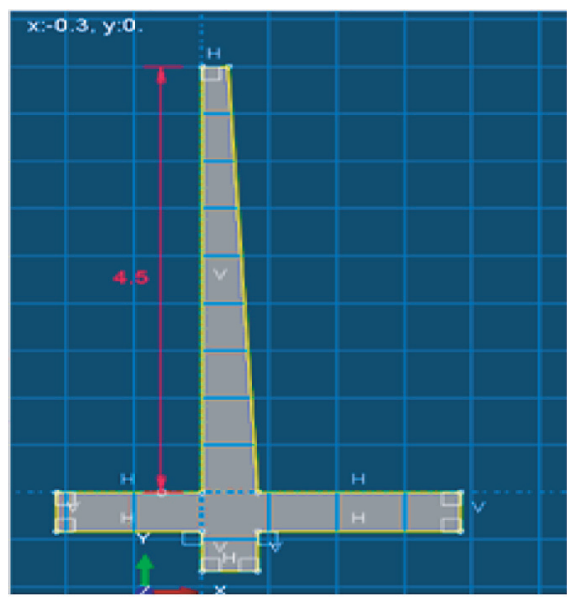

(a)

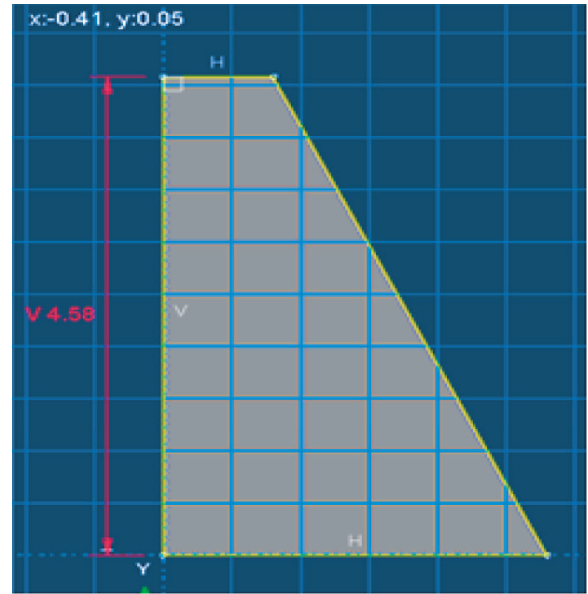

(b)

FIgURE 7: Geometry for cantilever and gravity retaining wall.

TABLE 7: Characteristics of materials.

\begin{tabular}{lccc}
\hline Properties & Concrete & Dry stone masonry & Steel \\
\hline Modulus of elasticity, $E_{c}\left(\mathrm{~N} / \mathrm{mm}^{2}\right)$ & 23500 & 14270 & 200000 \\
$f_{c}\left(\mathrm{~N} / \mathrm{mm}^{2}\right)$ & 25 & 49.3 & 415 \\
$\rho\left(\mathrm{kg} / \mathrm{m}^{3}\right)$ & 2400 & 2400 & 7850 \\
$\mathrm{M}$ & 0.2 & 0.2 & 0.3 \\
\hline
\end{tabular}

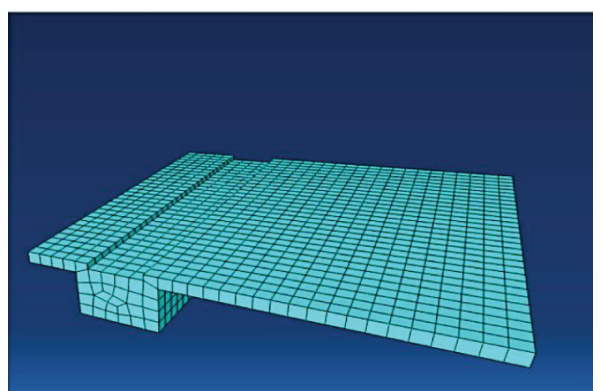

(a)

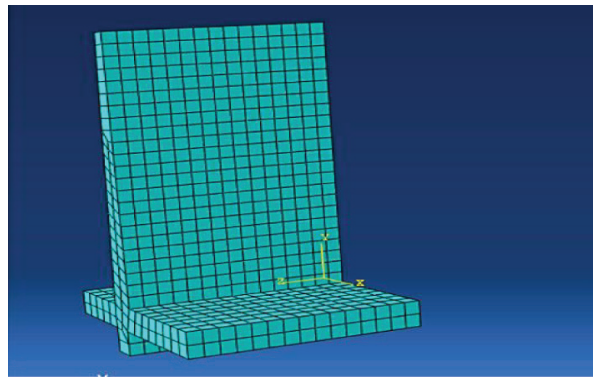

(c)

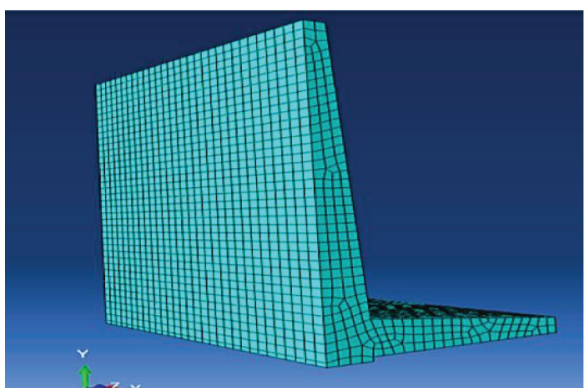

(b)

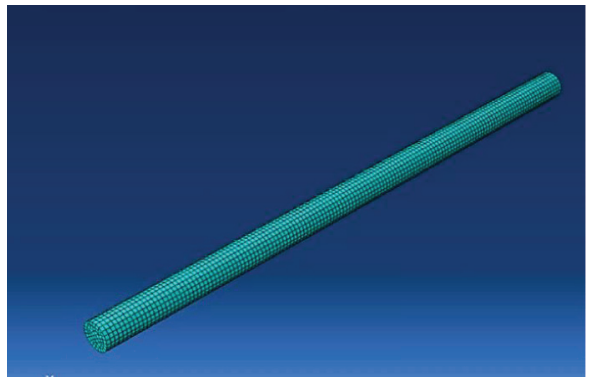

(d)

Figure 8: Meshing of (a) levelling pad, (b) precast wall panel, (c) cantilever retaining wall, and (d) anchor bars.

4.2. Stress Distribution and Deflection in Cantilevered Retaining Wall. In case of cantilever retaining walls, as shown in Figure 10(a), the stress was gradually increased in the bottom arm of the wall, and the maximum deflection as shown in Figure 10(b) was found at the top arm along the wall's height.
4.3. Stress Distribution and Deflection in Precast/Prefabricated Concrete Retaining Wall. In Figure 11(a), the distribution of stress in the prefabricated retaining wall was discovered to be gradually increased in the arm of the cantilever retaining wall, whereas the highest deflection was observed at the wall's top arm as shown in Figure 11(b). 


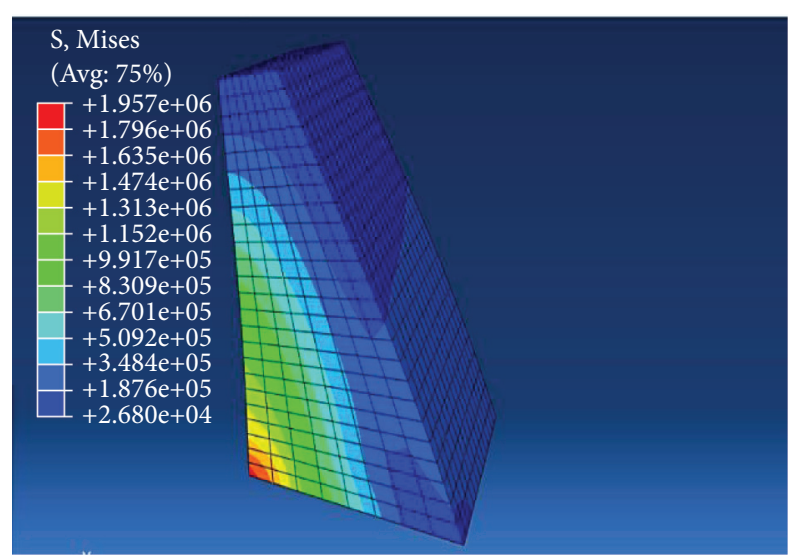

(a)

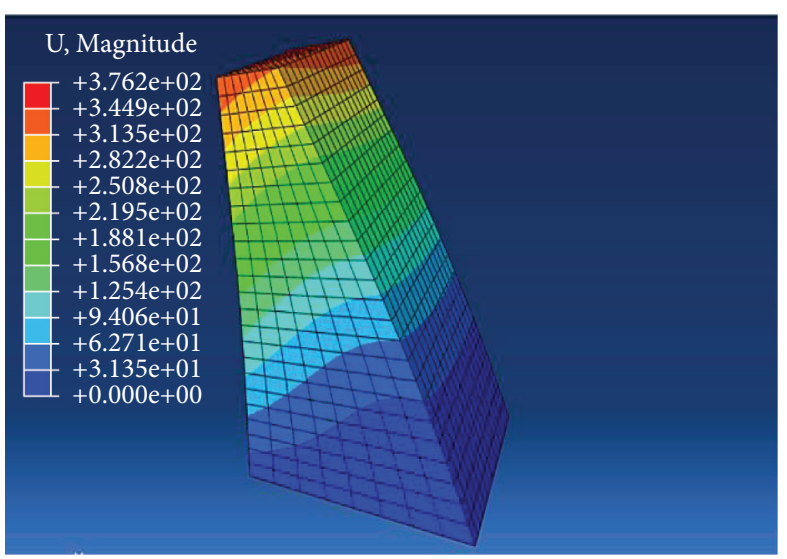

(b)

FIGURE 9: (a) Distribution of stress in gravity wall. (b) Deflection in gravity wall.

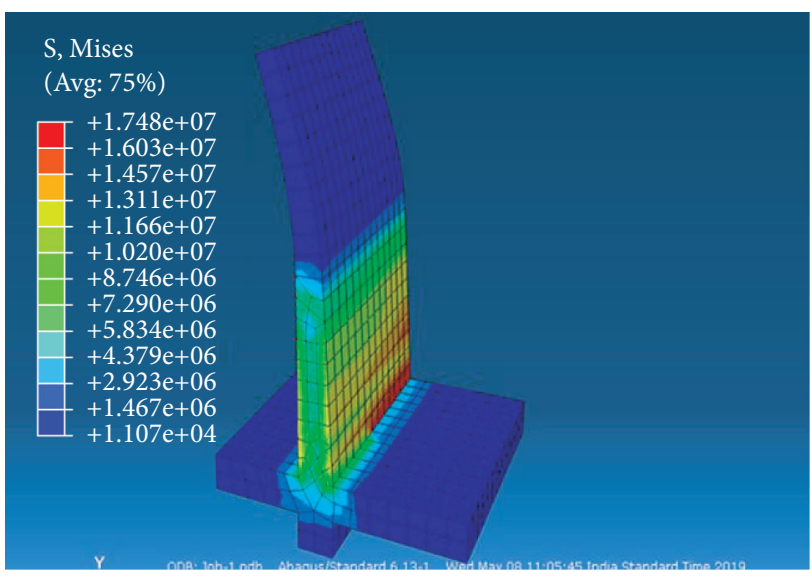

(a)

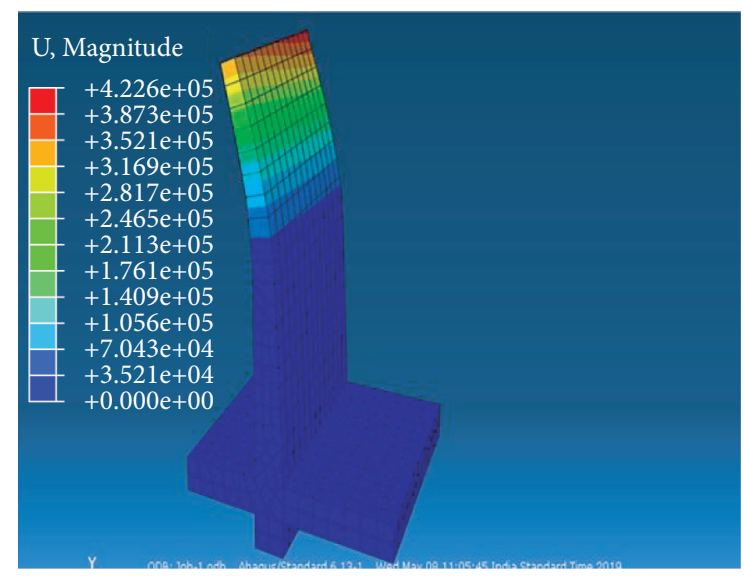

(b)

Figure 10: (a) Distribution of stress in cantilever retaining wall. (b) Deflection in cantilever retaining wall.

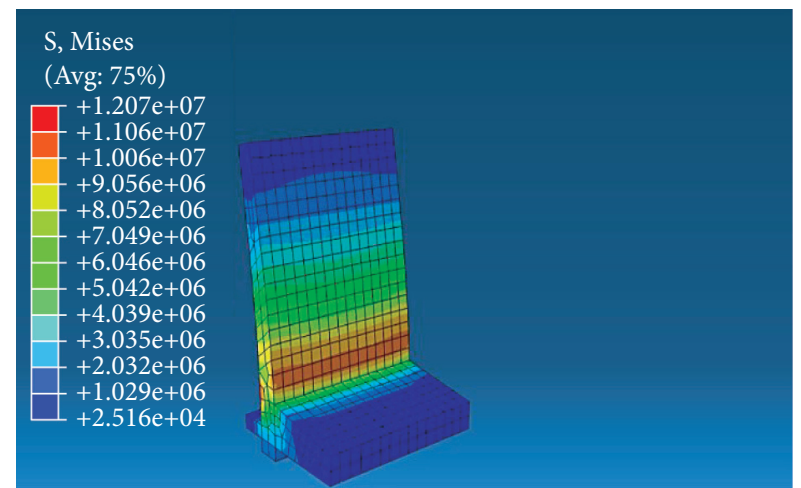

(a)

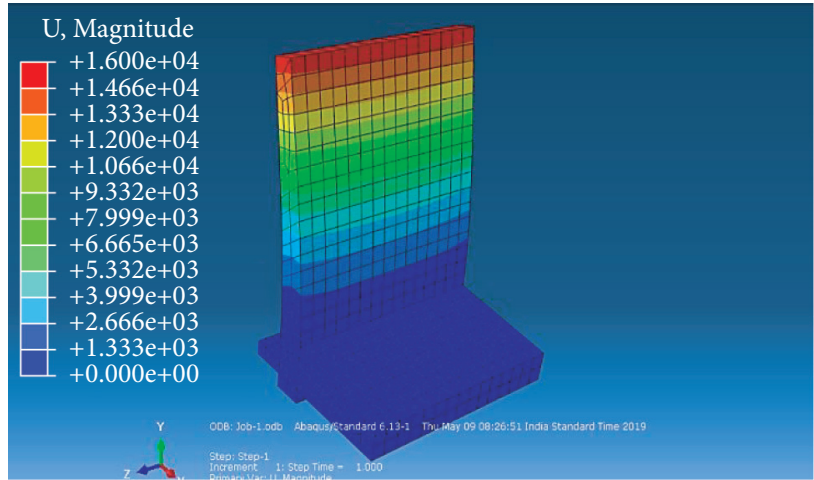

(b)

FIGURE 11: (a) Stress distribution in precast type retaining wall. (b) Deflection in precast type retaining wall.

Figures 12(a) and 12(b) show the distribution of stress and deflection along with the gravity wall's height. From Figure 12(a), it was observed that the stress was declining as the retaining wall's height was increasing and was found to be the highest on the bottom. Figure 12(b) shows the deflection diagram whose mode is the reverse of the stress diagram. The deformation in the gravity retaining wall was observed to be increased with raising the height of the 


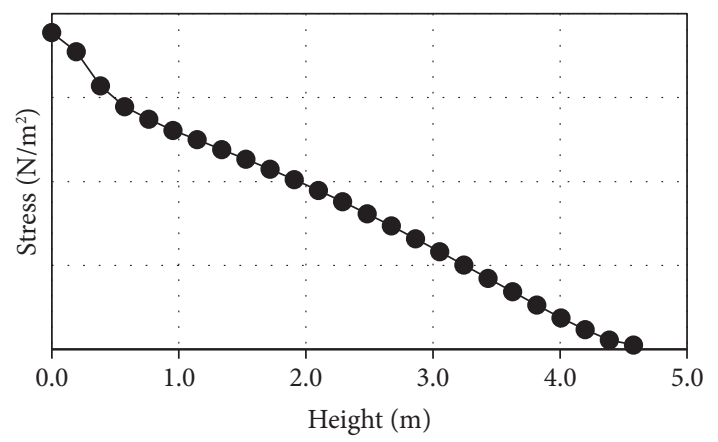

(a)

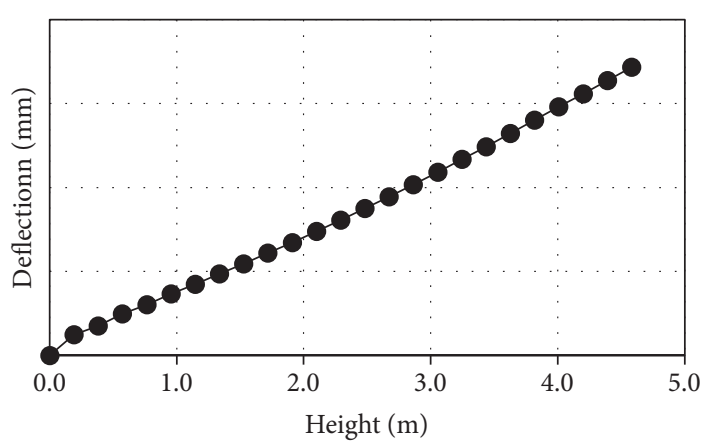

(b)

FIGURE 12: Behaviour of gravity retaining wall. (a) Stress distribution. (b) Deflection.

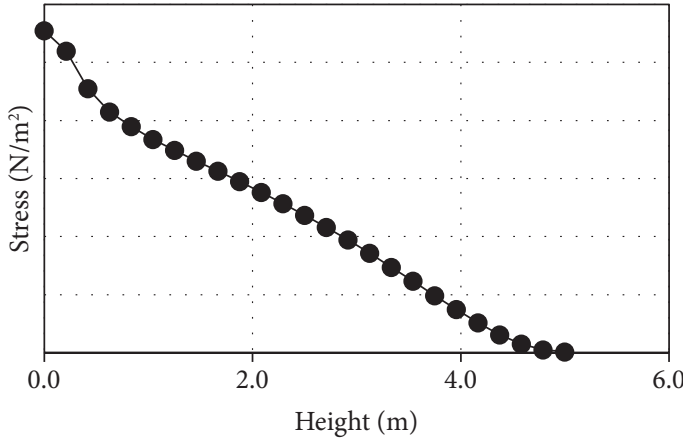

(a)

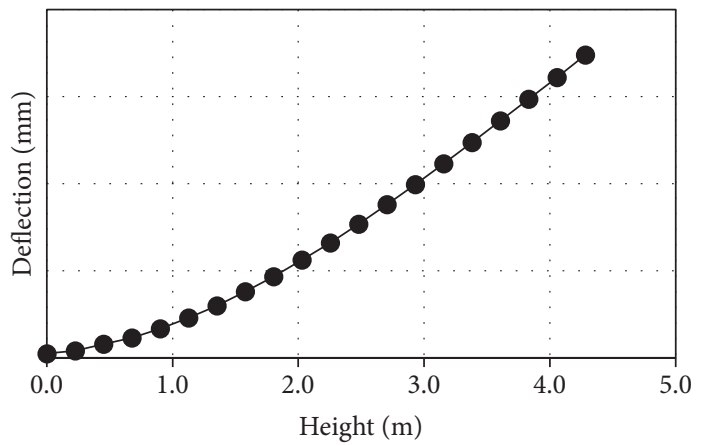

(b)

FIGURE 13: Behaviour of cantilever retaining wall along the height. (a) Stress distribution. (b) Deflection.

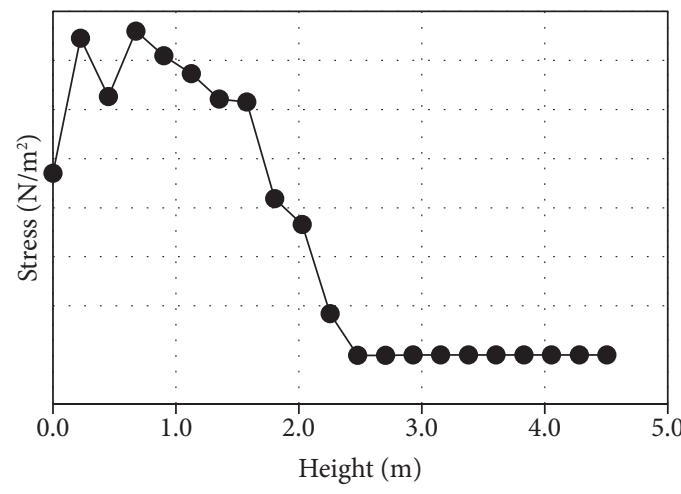

(a)

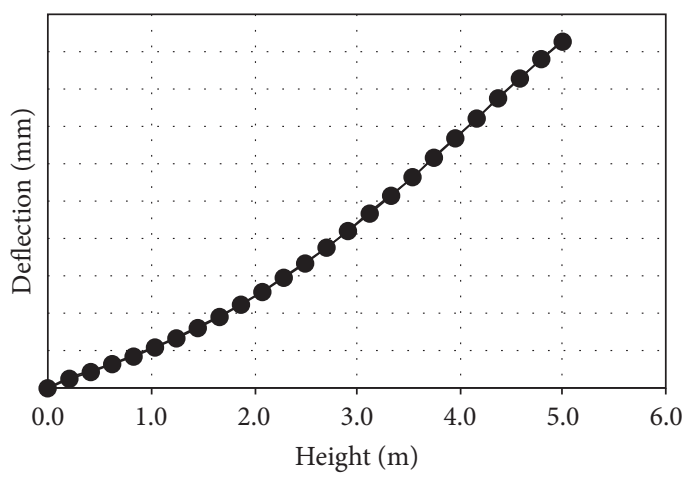

(b)

Figure 14: Behaviour of precast cantilever retaining wall along the height. (a) Stress distribution. (b) Deflection.

retaining wall, and the deflection value was the smallest at the bottom and attained the maximum while moving towards the wall's top part. This signifies that the walls are exposed to the highest deformation in the upper area. Similar behaviour of gravity and cantilever retaining wall was observed in terms of deflection and distribution of stress throughout the wall's height as shown in Figures 13(a) and 13(b). The stress distribution behaviour in the precast retaining wall was different as compared to the gravity type and cantilever type retaining wall. After $2.5 \mathrm{~m}$ of wall's height, the stress distribution in the precast retaining wall was found to become consistent as shown in Figure 14(a), while the deflection was found to be gradually rising as wall's height was increasing as shown in Figure 14(b).

A cantilever retaining wall (CRE), a prefabricated retaining wall (PCRE), and a gravity retaining wall (GRE) are all examples of retaining walls. The stress distribution and comparison of deviations of all walls studied in this research are shown in Figures 15(a) and 15(b). The distribution of stress and the deviation of the gravity retention walls are at 


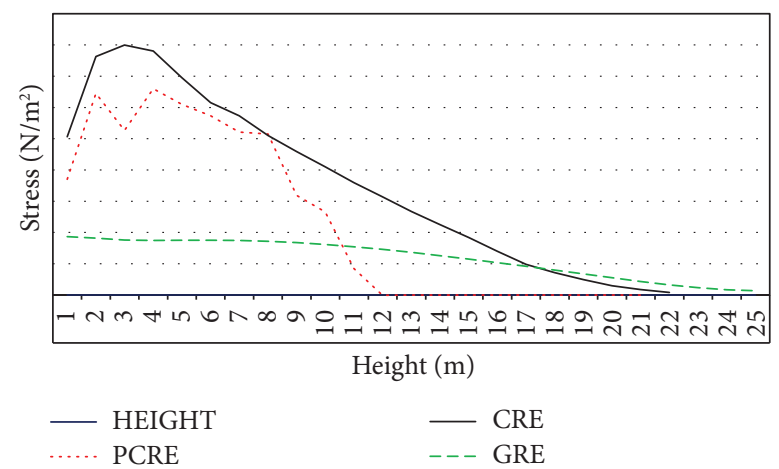

(a)

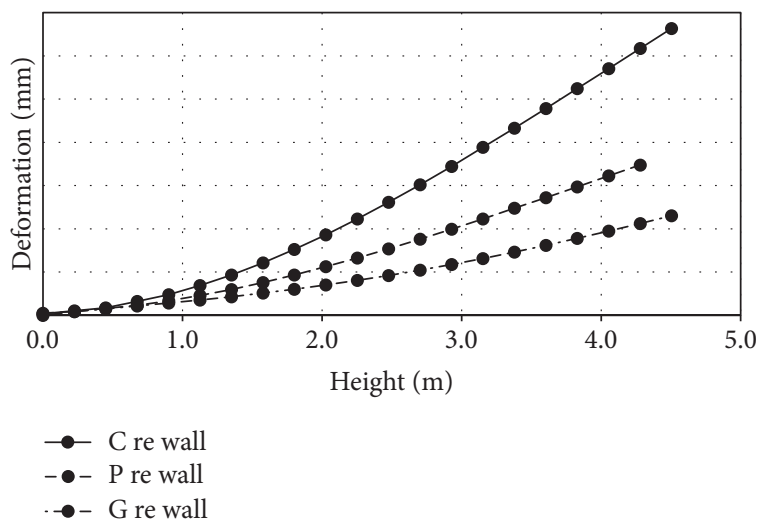

(b)

FIGURE 15: Behaviour of retaining wall along the height. (a) Stress distribution. (b) Deformation.

least three, but due to its natural size, a large amount of workforce, capital, and material supplies are required making it a completely noneconomic approach. However, if it is compared between the cantilever and the prefabricated retention wall, the deviation of the cantilevered wall is much larger than the prefabricated wall, and the value of stress is also minimized. Also, the prefabricated wall has a faster installation in comparison of cantilever and gravity type retaining wall.

\section{Conclusions}

This study analysed the stability of traditional and prefabricated retaining walls created for the same factors and the same payloads on a global scale. The analysis comes to the following conclusions:

(i) The level of stress on the bottom of the valve stem in the prefabricated retaining wall has been found to be decreased by about $21 \%$, and the deflection has been reduced by $35-40 \%$. Owing to the reduction in stress and deflection level, it is concluded that the prefabricated retaining walls are significantly more stable than traditional retaining walls in terms of total stability.

(ii) The stress distribution in gravity type and cantilever type retaining wall was declined with rising wall height, while the deflection was increased with the height and observed maximum deflection at the top.

(iii) The thickness of the lower bar has been reduced by $12 \%$, and the total volume of the precast wall has been reduced by a total of $9 \%$, making it more economical.

(iv) The wall system is expected to take 2-3 hours to build and needs very little effort.

\section{Data Availability}

The data used to support the findings of this study are available from the corresponding author upon request.

\section{Conflicts of Interest}

The authors declare that they have no conflicts of interest.

\section{References}

[1] K. Hatami, R. J. Bathurst, and P. D. Pietro, "Static response of reinforced soil retaining wall with non-uniform reinforcement," International Journal of Geometry, vol. 1-4, no. 477, 2001.

[2] J. E. Bowles, Foundation Analysis and Design, McGraw-Hill, NY, USA, 2002.

[3] S. H. Choi, "A study on the stability analysis of earth reinforcement walls constructed in the cutting faces," $\mathrm{Ph}$. D. Thesis, University of Hongik, Seoul, South Korea, 2013.

[4] S. P. Yun and J. S. Lim, "Comparison of the kind and characteristics of the cut slope retaining wall system," Journal of the Sangyong Construction Technology, vol. 58, pp. 35-40, 2011.

[5] M. S. Al-Zoubi, "Reliability - based determination of the coefficients of lateral earth pressure on retaining walls subjected to seismic loading," Jordan Journal of Civil Engineering, vol. 9, no. 4, pp. 421-434, 2015.

[6] K. Hazirbaba, O. Mugheida, and G. Abu-Lebdeh, "A critical review on seismic design of earth-retaining structures," Jordan Journal of Civil Engineering, vol. 13, no. 1, pp. 61-69, 2019.

[7] S. Goel and N. R. Patra, "Effect of arching on active earth pressure for rigid retaining walls considering translation mode," International Journal of Geomechanics, vol. 8, no. 2, pp. 123-133, 2008.

[8] S. C. Soon and A. Drescher, "Nonlinear failure criterion and passive thrust on retaining walls," International Journal of Geomechanics, vol. 7, no. 4, pp. 318-322, 2007.

[9] C. S. Vieira, M. d. L. Lopes, and L. M. Caldeira, "Earth pressure coefficients for design of geosynthetic reinforced soil structures," Geotextiles and Geomembranes, vol. 29, no. 5, pp. 491-501, 2011

[10] V. R. Greco, "Active earth thrust by backfills subject to a line surcharge," Canadian Geotechnical Journal, vol. 42, no. 5, pp. 1255-1263, 2005.

[11] V. R. Greco, "Lateral earth pressure due to backfill subject to a strip of surcharge," Geotechnical \& Geological Engineering, vol. 24, no. 3, pp. 615-636, 2006.

[12] M. Ahmadabadi and A. Ghanbari, "New procedure for active earth pressure calculation in retaining walls with reinforced 
cohesive-frictional backfill," Geotextiles and Geomembranes, vol. 27, no. 6, pp. 456-463, 2009.

[13] A. Azad, S. S. Yasrobi, and A. Pak, "Seismic active pressure distribution history behind rigid retaining walls," Soil Dynamics and Earthquake Engineering, vol. 28, no. 5, pp. 365-375, 2008.

[14] A. S. Al-Homoud and R. V. Whitman, "Seismic analysis and design of rigid bridge abutments considering rotation and sliding incorporating non-linear soil behavior," Soil Dynamics and Earthquake Engineering, vol. 18, no. 4, pp. 247-277, 1999.

[15] M. Geng, D. B. Wang, P. Y. Li, and C. Gao, "Numerical simulation of dynamic behavior of reinforced subgrade," Journal of water resources and architectural engineering, vol. 16, no. 1, pp. 211-215, 2018.

[16] Y. Jiang, J. Han, J. Zornberg, R. L. Parsons, D. Leshchinsky, and B. Tanyu, "Numerical analysis of field geosyntheticreinforced retaining walls with secondary reinforcement," Géotechnique, vol. 69, no. 2, pp. 122-132, 2019.

[17] K. Senthil, M. A. Iqbal, and A. Kumar, "Behavior of cantilever and counterfort retaining walls subjected to lateral earth pressure," International Journal of Geotechnical Engineering, vol. 8, no. 2, pp. 167-181, 2014.

[18] F. Ren, Q. Huang, and G. Wang, "Shaking table tests on reinforced soil retaining walls subjected to the combined effects of rainfall and earthquakes," Engineering Geology, vol. 267, Article ID 105475, 2020.

[19] S. Li, X. Cai, H. Xu, L. Jing, X. Huang, and C. Zhu, "Dynamic behaviour of reinforced soil retaining wall under horizontal seismic loading," IOP Conference Series: Earth and Environmental Science, vol. 569, Article ID 012001, 2020.

[20] B. Nematollahi, Y. L. Voo, and J. Sanjayan, "Design and construction of a precast ultra-high performance concrete cantilever retaining wall," in Proceedings of the First International Interactive Symposium on UHPC-2016, Des Moines, Iowa, July 2016.

[21] T. Abood, E. Y. Eldawi, and F. R. E. Abdulrahim, "Design of cantilever retaining wall with $4 \mathrm{~m}$ height," International Journal of Civil and Structural Engineering Research. ISSN, vol. 3, no. 1, pp. 2348-7607, 2015.

[22] L. Xu and H. I. Ling, "Centrifuge modeling and numerical analysis of reinforced soil retaining walls with concrete block facing," Transportation Infrastructure Geotechnology, vol. 7, no. 3, pp. 405-425, 2020.

[23] P. Zastrow, F. Molina-Moreno, T. García-Segura, J. V. Martí, V. Yepes, and V. Yepes, "Life cycle assessment of cost-optimized buttress earth-retaining walls: a parametric study," Journal of Cleaner Production, vol. 140, pp. 1037-1048, 2017.

[24] D. Gaudio, L. Masini, and S. Rampello, "A performance-based approach to design reinforced-earth retaining walls," Geotextiles and Geomembranes, vol. 46, no. 4, pp. 470-485, 2018.

[25] Is 14458, "Guidelines for retaining wall for hilly-area," Part 2 Design Of Retaining/Breast Walls, Bureau Of Indian Standards, Manak Bhawan, Old Delhi, 1997.

[26] J. Vlcek, "Internal stability analyses of geosynthetic reinforced retaining walls," Procedia Engineering, vol. 91, pp. 346-351, 2014.

[27] Y. Zhou, F. Chen, and X. Wang, "Seismic active earth pressure for inclined rigid retaining walls considering rotation of the principal stresses with pseudo-dynamic method," Int. J. Geomech. ASCE, vol. 18, pp. 1-9, 2018.

[28] H. C. Alhajj, D. Dias, M. Sadek, O. Jenck, and F. Hage Chehade, "Seismic analysis of geosynthetic-reinforced retaining wall in cohesive soils," Geotextiles and Geomembranes, vol. 47, no. 3, pp. 315-326, 2019.
[29] Xi Xu and Yu Huang, "Parametric study of structural parameters affecting seismic stability in slopes reinforced by pile-anchor structures," Soil Dynamics and Earthquake Engineering, vol. 147, Article ID 106789, 2021.

[30] M. Geng, "A short review on the dynamic characteristics of geogrid-reinforced soil retaining walls under cyclic loading," Advances in Materials Science and Engineering, vol. 2021, Article ID 5537912, 10 pages, 2021.

[31] J. Han, Y. Jiang, and C. Xu, "Recent advances in geosyntheticreinforced retaining walls for highway applications," Frontiers of Structural and Civil Engineering, vol. 12, no. 2, pp. 239-247, 2018.

[32] M. Djabri and S. Benmebarek, "FEM analysis of back-to-back geosynthetic-reinforced soil retaining walls," International Journal of Geosynthetics and Ground Engineering, vol. 2, no. 3, p. 26, 2016. 